\title{
PAEDIATRIC SURGERY AT A REGIONAL HOSPITAL
}

\author{
McKevitt E C, Schwarz R, Schneidereit N
}

\section{ABSTRACT}

Infants and young children are at particular risk from anaesthesia and surgery. Some have suggested that these patients only be cared for by those with specialty paediatric surgical and anaesthetic training. In district hospitals and the developing world this is often not possible. We have undertaken a prospective study to determine the mortality and morbidity rate for children 0 to 5 years undergoing surgery at Western Regional Hospital (WRH) in Pokhara, Nepal. During 1999 there were 354 patients in this age group undergoing surgery. Surgical procedures were done in general surgery (covering urology, plastics and neurosurgery as well), orthopaedics, ENT and ophthalmology. There were 6 deaths for a mortality rate of $1.7 \%$. Seven patients had in hospital complications and significant management problems were identified in four patients.

In conclusion, although there is no dedicated paediatric surgical unit at WRH, children undergoing surgery at this hospital have acceptable morbidity and mortality rates. An improvement in timely presentation, diagnosis, treatment and intraoperative monitoring may further improve these results.

Key Words: Paediatric Surgery, Regional Hospital, Morbidity, Mortality, Nepal.

\section{INTRODUCTION}

Infants and young children pose a particular challenge to both surgeon and anaesthetist. The mortality rate relating to anaesthesia in children is 3-4 times the rate of that in the general population. ${ }^{1}$ Young children are at particular risk from anaesthesia due to the small size of their airway, respiratory secretions, and precise fluid requirements. $^{2}$
An enquiry into the perioperative death of infants and children was undertaken in Great Britain in 1987. ${ }^{3}$ The recommendations from this inquiry were that children and infants should be cared for by anaesthetists and surgeons with speciality training in paediatrics and regular paediatric practise. $^{4}$

Large urban centres have dedicated children's hospitals and wards, but these facilities are often not available in smaller community hospitals and

Address for correspondence : $\quad$ Richard J. Schwarz, F.R.C.S.

Box 5, Pokhara, Nepal. 
in many hospitals in the developing world. In Nepal the majority of the population are served by hospitals who do not have surgeons with paediatric surgical training. At Western Regional Hospital in Pokhara infants and small children undergoing surgery are cared for on the general surgical and orthopaedic ward. There is no intensive care facility and no paediatric monitoring equipment. In light of the western recommendations a study was undertaken at WRH to look at outcomes and problems of children 5 years and younger undergoing surgery at our hospital.

\section{MATERIALS AND METHODS}

A prospective review of patients $0-5$ years undergoing surgery at Western Regional Hospital (WRH) was performed. WRH is the referral centre for the Western Region in Nepal and the primary hospital for Kaski district. The catchment population is approximately 500,000 although referral patterns are difficult to determine. Data was collected from January 1, 1999 to December 31, 1999. Patients who did not undergo surgery or patients who died preoperatively were excluded from the study. Patient demographics, operations performed, type of anaesthesia given, in hospital complications, problems, and outcomes were reviewed.

\section{RESULTS}

A total of 354 patients met study criteria. There were 226 male patients and 128 female patients.

Table I: Age of paediatric surgical patients at WRH in 1999.

\begin{tabular}{|c|c|}
\hline AGE & NUMBER OF PATIENTS \\
\hline$<1$ & 57 \\
\hline 1 & 63 \\
\hline 2 & 45 \\
\hline 3 & 38 \\
\hline 4 & 63 \\
\hline 5 & 86 \\
\hline
\end{tabular}

The distribution of Patients by age is shown in table I. In the <1 year age category there were 20 patients < 4 months, 17 patients 4-6 months, and 20 patients 6 months to 1 year.

Operations performed are classified by speciality in table II. They were performed by multiple

Table II: Operations performed at WRH on Patients 0-5 years for the year 1999.

\begin{tabular}{|c|c|c|}
\hline $\begin{array}{c}\text { SURGICAL } \\
\text { SPECIALITY }\end{array}$ & OPERATION & CASES \\
\hline GENERAL & Incision and Drainage & 49 \\
\hline \multirow[t]{12}{*}{$(151)$} & Hemioraphy & 40 \\
\hline & Repair/debride wound & 15 \\
\hline & Removal FB esophagus & 9 \\
\hline & Polypectomy & 8 \\
\hline & Excision skin lesion & 6 \\
\hline & Laparotomy & 4 \\
\hline & Laparotomy for Intussusception & 4 \\
\hline & Appendectomy & 3 \\
\hline & Biopsy & 3 \\
\hline & Hirschsprungs- colostomy & 3 \\
\hline & Ramstead- Pyloric Stenosis & 2 \\
\hline & Repair Rectovaginal fistula & 1 \\
\hline PLASTICS & Burn- debride and grafting & 33 \\
\hline \multirow[t]{4}{*}{$(91)$} & Cleft lip/palate & 29 \\
\hline & Facial operations & 16 \\
\hline & Hand operations & 8 \\
\hline & Release bum contracture & 5 \\
\hline ORTHOPAEDICS & Reduction of fracture/POP & 38 \\
\hline \multirow[t]{2}{*}{$(55)$} & ORIF/repair deformity & 12 \\
\hline & Debride osteomyelitis/Septic arthritis & 5 \\
\hline UROLOGY & Phimosis- circumcision or stretch & 18 \\
\hline \multirow[t]{2}{*}{$(23)$} & cystolithotomy (3open) & 4 \\
\hline & nephrostomy tube & 1 \\
\hline OPHTHAMOLOGY & repair injury to eye & 13 \\
\hline \multirow[t]{2}{*}{$(19)$} & enucleation & 1 \\
\hline & other & 5 \\
\hline OTOLARYNGOLOGY & drainage for mastoiditis & 4 \\
\hline \multirow[t]{2}{*}{$(10)$} & myringostomy & 5 \\
\hline & tracheostomy & 1 \\
\hline NEUROSURGERY & repair meningomyelocele & 2 \\
\hline (3) & Burr hole & 1 \\
\hline
\end{tabular}

FB = foreign body

POP = plaster of paris

ORIF = open reduction internal fixation

surgeons from the departments of general surgery, plastic surgery, orthopaedic surgery. Ophthalmology and Otolaryngology. The majority of major general surgical, plastic surgical and neuro surgical procedures were done by a single surgeon. 
178 patients received general anaesthesia, 163 patients received IV anaesthesia in the absence ofendotracheal intubation 11 patients received IM ketamine, and one patient received local anaesthetic (for the drainage of an abscess). One patient was converted from IV anaesthesia to general anaesthesia.

Out of 354 patients there were 6 deaths $(1.7 \%)$ These are outlined in table III. Deaths were

Table III: Paediatric Surgical Deaths at WRH in 1999.

\begin{tabular}{|c|c|c|c|c|}
\hline \begin{tabular}{|l|} 
Pat- \\
ient
\end{tabular} & \begin{tabular}{|l|} 
TIMING OF \\
PROBLEM \\
\end{tabular} & $\begin{array}{c}\text { TIMING OF } \\
\text { DEATH }\end{array}$ & Age & DIAGNOSIS \\
\hline 1 & PREOP/OP & $\begin{array}{l}\text { Died immediately } \\
\text { post op }\end{array}$ & $\begin{array}{c}4 / 1 \\
2 \\
\end{array}$ & Intussusception \\
\hline 2 & & Died in recovery & 1 & Epiglottitis \\
\hline 3 & & Died on induction & 4 & Perforated GIT \\
\hline 4 & OPERATIVE & $\begin{array}{l}\text { Intraoperative } \\
\text { cardiac arrest }\end{array}$ & $\begin{array}{c}3 / 1 \\
2\end{array}$ & Cleft lip/palate \\
\hline 5 & POSTOP & Died sepsis & 1 & Burn \\
\hline 6 & & $\begin{array}{l}\text { Died dehydration } \\
\text { / sepsis }\end{array}$ & 5 & Burn \\
\hline
\end{tabular}

\section{GIT $=$ gastrointestinal tract}

categorized as preoperative/operative/postoperative according to the timing of the largest contributing factor to the death. Seven patients had complications which are outlined in table IV. Four patients had significant management problems.

Table IV: Complications experienced by paediatric surgical patients in 1999 at WRH.

\begin{tabular}{|l|c|c|}
\hline \multicolumn{1}{|c|}{ MORBIDITY } & AGE & DIAGNOSIS \\
\hline $\begin{array}{l}\text { Intraoperative cardiac } \\
\text { arrest }\end{array}$ & $2 / 12$ & $\begin{array}{c}\text { Rectovaginal } \\
\text { fistula }\end{array}$ \\
\hline Laryngospasm & $8 / 12$ & Burn \\
\hline Persistent tachycardia & 5 & Empyema \\
\hline $\begin{array}{l}\text { Obstruction and } \\
\text { wound infection }\end{array}$ & $6 / 12$ & Intussusception \\
\hline Slough 50\% SSG & $2 / 12$ & Burn \\
\hline Wound Infection & 5 & $\begin{array}{c}\text { Perforated } \\
\text { Appendix }\end{array}$ \\
\hline Wound Infection & 5 & Skin lesion \\
\hline
\end{tabular}

SSG = split thickness skin graft
These are outlined in table V. These eleven patients

Table V: Significant Management Problems in paediatric surgical patients in 1999 at WRH.

\begin{tabular}{|l|c|c|}
\hline \multicolumn{1}{|c|}{ PROBLEM } & AGE & DIAGNOSIS \\
\hline $\begin{array}{l}\text { IV fluid overload/ wrong } \\
\text { IV solution }\end{array}$ & $11 / 12$ & Intussuception \\
\hline $\begin{array}{l}\text { IV fluid overload/ wrong } \\
\text { IV solution }\end{array}$ & $2 / 12$ & Burn \\
\hline IV fluid not given & $1 / 12$ & Pyloric Stenosis \\
\hline Very slow recovery & 1 & Cleft lip/palate \\
\hline
\end{tabular}

IV = intravenous

all recovered from their complications uneventfully and were discharged home in good condition.

\section{DISCUSSION}

A wide variety of surgery has been performed for children in the age group 0-5 years at WRH, with an overall mortality of $1.7 \%$. There were 3 deaths categorised as preoperative/ operative. The first child had been admitted to the paediatrics ward. After 8 days the diagnosis of intussusception was made and the child underwent laparotomy and bowel resection. The child died immediately post operatively, apparently of overwhelming sepsis, in part from the late diagnosis. Patient 2 was a one year old child who presented with respiratory distress and was brought to the operating theatre for intubation. The child was anaesthetised but could not be intubated. The child became increasingly hypoxic and the diagnosis of epiglottitis was made. A tracheostomy was performed. The child was ventilated and subsequently died. Patient 3 was a 4 year old child who presented to the hospital with a 4 day history of blunt trauma with injuries to the abdomen, chest and head. He was brought to the operating theatre with peritonitis for laparotomy and arrested on induction. Laparotomy showed a perforated ileum. Ongoing resuscitation was unsuccessful. This death was mostly due to sepsis from late presentation, 
although in retrospect, inadequate preoperative hydration may also have been a factor. In each of these three cases timely preoperative diagnosis and operation may have prevented death.

The one intraoperative death occurred in an 3 month old child who was undergoing a cleft lip and palate repair. The anaesthetist had been called from the OT and the child was left with the anaesthetic attendant. On re-evaluation by the anaesthetist the child was found to be bradycardic and then had a cardiac arrest. Increased number of anaesthetists or better trained staff may have prevented this death.

The two postoperative deaths were in children with extensive burns. In one case the child developed an ileus due to sepsis and in the other case the child's dressings were not covered and the child became dehydrated and died from a combination of sepsis and dehydration. Covering the dressings with plastic material may help prevent fluid evaporation from large open wounds. Careful monitoring of fluid status in these patients is essential.

A total of 6 deaths out of the 354 children presenting for operation (1.7\% mortality) at WRH demonstrates that conditions for children are reasonably safe. Improvement in preoperative diagnosis, and paediatric monitoring in the OT and recovery area may further improve the mortality rate.

The morbidity rate of $2.3 \%$ is lower than expected. The complications listed in table 4 are difficult to avoid. Only in-hospital complications were recorded as follow-up is very unreliable in our patient population. The one child who suffered an intraoperative cardiac arrest was resuscitated immediately and recovered uneventfully. The cause of the arrest was not determined. This case further illustrates the importance of close monitoring by the anaesthetist. There were three patients who had wound infections in hospital, giving an in-hospital wound infection rate of $1 \%$. Veronique reported $^{5}$ an in hospital wound infection following hernia repair in Sri Lanka as $2 \%$. Our in hospital infection rate from this group was $0 \%$, however we had a smaller sample size. Our in hospital infection rate for clean and clean contaminated cases was $<1 \%$. Although follow-up data for some outpatient cases is lacking, it would be expected that the number to be in keeping with the rates quoted for clean cases $(1.5 \%)$ and clean contaminated $(2-5 \%)$ in the literature. ${ }^{6}$

The problems outlined in table 5 involve administration of IV fluids. The two patients with fluid overload were given the wrong volume and type of IV fluid and developed peripheral edema. They recovered uneventfully when the problem was corrected. The child who did not receive the IV fluid ordered recovered more slowly than expected, but there was no adverse outcome. The true extent of this problem is difficult to determine other children may not have received IV fluids as ordered, but may not have been identified by our study. Fluid and electrolyte administration is a important source of morbidity and mortality in children undergoing surgery. ${ }^{7,8}$ Staff at all levels need an understanding of principles of fluid and electrolyte management in infants and children and patients need ongoing reassessment of their fluid and electrolyte requirements. Doctors involved in paediatric surgery in non-speciality centres need to be very clear in their orders and check frequently with nurses on changing shifts to ensure orders are being carried out properly. Fluid orders should be written for short periods (4 to 6 hours) rather than for 24 hour periods. Continuing education of staff is necessary in which the surgeon must be involved. Good recovery facilities are required to ensure safe post-operative management. 
Although no surgeon at WRH has dedicated training in paediatric surgery a total mortality, morbidity, and significant problem rate of $4.8 \%$ in the age group is reasonable and supports the continued care of young children with surgical diseases at WRH. Each case must be judged individually as to whether the child can be appropriately managed at this centre or whether transfer is required.

\section{CONCLUSIONS}

A wide variety of surgery is performed at WRH on patients 5 years of age and younger. In spite of the fact that there is no designated paediatric surgery ward at WRH and the OT lacks good paediatric monitoring equipment, the morbidity and mortality rates are lower than we expected for this age group. Although consideration must always be given to transferring patients to specialised centres for management, this study shows that young children undergoing surgery at WRH do reasonably well. Improvement in timely preoperative diagnosis, intraoperative monitoring and post-operative fluid and electrolyte management may further improve the outcomes following surgery in this age group at WRH.

\section{REFERENCES}

1. Motoyama E K. Safety and outcome m pediatric anesthesia./n Motoyama EK, Davis PJ(eds) : Smith's Anesthesia for Infants and Children. St Louis, CV Mosby, 1990, pp 847-856.

2. Hatch D, Fletcher M. Anaesthesia and the Ventilatory System in Infants and Young Children. Br J Anaeth 68:398-400, 1992

3. Buck N, Devlin HB, Lum JN. The Report of the Confidential Enquiry into Perioperative Deaths. London: Nuffield Provincial Hospitals Trust and the King Edward's Hospital Fund for London, 1987.

4. Gough MM. Perioperative Deaths amoung children. BrMedJ 300:1606, 1990.

5. Veronique L. Prospective Study on Wound Infection rate after Hernia Repair in Bathcaloa General Hospital (Sri Lanka). Medical News. November 1999.

6. Way LW (ed). Current Surgical Diagnosis and Treatment. Norwalk, Appleton and Lange, 1994.

7. Filston HC. Fluid and electrolyte management in the pediatric surgical patient. Surg Clin NA72 (6) :1189-1205, 1992.

8. Mahaffey SM. Neonatal and Pediatric Physiology /nGreenfield LJ: Surgery Scientific Principles and Practice. 2nd ed. Philadelphia: Lippincott-Raven, 1997. 